\title{
Sodium Intake, Dietary Knowledge, and Illness Perceptions of Controlled and Uncontrolled Rural Hypertensive Patients
}

\author{
Aziz Kamran, ${ }^{1,2}$ Leila Azadbakht, ${ }^{3}$ Gholamreza Sharifirad, ${ }^{2}$ \\ Behzad Mahaki, ${ }^{4}$ and Afshan Sharghi ${ }^{5}$ \\ ${ }^{1}$ Public Health Department, School of Health, Ardabil University of Medical Sciences, Ardabil 5618953141, Iran \\ ${ }^{2}$ Health Education \& Promotion Department, School of Health, Isfahan University of Medical Sciences, Isfahan 817473461, Iran \\ ${ }^{3}$ Food Security Research Center \& Department of Community Nutrition, School of Nutrition and Food Science, \\ Isfahan University of Medical Sciences, Isfahan, Iran \\ ${ }^{4}$ Department of Epidemiology and Biostatics, School of Public Health, Isfahan University of Medical Sciences, Isfahan, Iran \\ ${ }^{5}$ Community Medicine Department, School of Medicine, Ardabil University of Medical Sciences, Ardabil, Iran
}

Correspondence should be addressed to Gholamreza Sharifirad; sharifirad@hlth.mui.ac.ir

Received 18 October 2013; Revised 3 December 2013; Accepted 17 December 2013; Published 4 February 2014

Academic Editor: Mandy Kwan

Copyright (C) 2014 Aziz Kamran et al. This is an open access article distributed under the Creative Commons Attribution License, which permits unrestricted use, distribution, and reproduction in any medium, provided the original work is properly cited.

Introduction and Objectives. Nutritional knowledge of the patients is important in dietary adherence. This study aimed to determine the relationship between illness perceptions and nutritional knowledge with the amounts of sodium intake among rural hypertensive patients. Methods. In a cross-sectional study, 671 hypertensive patients were selected in a multistage random sampling from the rural areas of Ardabil city, Iran, in 2013. Data were collected using a questionnaire consisting of four sections and were analyzed using Pearson correlation and multiple linear regressions by SPSS-18. Results. The mean of sodium intake in the uncontrolled hypertensive patients was $3599 \pm 258 \mathrm{mg} /$ day and significantly greater than controlled group $(2654 \pm 540 \mathrm{mg} / \mathrm{day})$ $(P<0.001)$. Knowledge and illness perceptions could predict $47.2 \%$ of the variation in sodium intake of uncontrolled group. A significant negative relationship was found between knowledge and illness perceptions of uncontrolled hypertensive patients with dietary sodium intake $(r=-0.66, P<0.001$ and $r=-0.65, P<0.001$, resp.). Conclusion. Considering the fact that patients' nutritional knowledge and illness perceptions could highly predict their sodium intake, the importance of paying more attention to improve patients' information and perceptions about hypertension is undeniable, especially among the uncontrolled hypertensive patients.

\section{Introduction}

Excess sodium intake is associated with increased blood pressure [1]. High blood pressure is a major cause of cardiovascular disease worldwide, and recent studies showed that there is a linear correlation between blood pressure and cardiovascular disease [2]. In recent decades rapid social and economic changes have led to the increment in prevalence of cardiovascular risk factors such as blood pressure in Mediterranean and Middle Eastern countries. Additionally, according to what different studies report, the prevalence of hypertension has been reported to be 10 to $17 \%$ in these region countries [3]. Different results have been reported by several studies conducted in Iran. In general, it can be said that 25 to 35 percent of adults are affected by hypertension [4]. Because of its high prevalence, this disease is important; however, its importance has been doubled due to the fact that hypertension is an uncontrolled disease [5]. One of the most important factors which play a prominent role in controlling the disease is patient's adherence.

The World Health Organization defines adherence as the agreement between an individual's medication-related behaviors and following nutritional and lifestyle changes recommended by health care providers [6]. Adherence or orders and information compliance are influenced by patient's beliefs and their health conditions [7]. Some studies have 
shown negative attitudes of hypertensive patients toward their disease. These perceptions may also be important in patient compliance and performance improvement [8]. However, if the patient thinks that hypertension is a controllable disease, following the recommendations may be more likely [9].

Meanwhile, some studies have reported that trivializing the illness of patient is one of the reasons behind uncontrolled blood pressure $[10,11]$ and self-care is not satisfactory in these patients [12-14]. The role of nutrition in disease control is undeniable and diet is one of the most effective nonpharmacological strategies and studies evidenced that healthy nutrition has beneficial effects on cardiometabolic parameters [1517], but behavior change and maintenance are not easy [18] because the greatest responsibility in dietary adherence is on the patients [19].

But, unfortunately, there are several conflicting evidences and most of the patients do not pay attention to dietary care instructions, only less than half of the patients have accepted healthy diet as part of their treatment [20], and studies have indicated wrong eating habits among them [21-23]. It seems that unhealthy behavior is rooted in misperceptions and incorrect knowledge of the nature of disease and its related nutritional issues, since poor knowledge of patients has been introduced as one of the reasons for the lack of blood pressure control $[24,25]$.

The main source of sodium intake in Iran is salt added at the table and in cooking, since processed foods in rural areas are not used, sodium added to these foods does not have an important role; therefore, knowledge of patients about the salt and its role in their illness can play a prominent role in dietary behavior. For this reason, the evaluation of knowledge related to hypertension in these patients is an integral part of overall health care activities [26] since knowledge has been introduced as an outcome of patients' education in interventional studies $[27,28]$. The highest knowledge in these patients is associated with lower rates of quitting interventional programs and higher adherence to treatment and better control of the disease [26].

Therefore, considering the importance of nutrition in the management of hypertension and the key role of illness perceptions and knowledge in patient's adherence to nutrition and disease control, this study was conducted to determine the relationship between illness perceptions and salt knowledge with dietary sodium intake among rural hypertensive patients in the city of Ardabil in 2013.

\section{Methods}

This is a cross-sectional study conducted among 671 hypertensive patients who were referred to rural health care centers in Ardabil city, Iran, in 2013. Ardabil city is located in northwest of Iran, near Iran-Azerbaijan border. Two-stage random sampling method was used to achieve our total sample. Out of 13 health centers available in the rural area, 6 were selected during first stage randomly; then, in the second stage, participants from each center were chosen randomly from patients' records. After thoroughly explaining about the objectives of the study, we requested their willingness to participate in the study, and then after they agreed they were enrolled in the study. Men did not show more willingness to participate in the study and complete the questionnaire, whereas women were overrepresented.

The criteria for inclusion consisted of disease diagnosed by a physician and patient aged between 30 and 60 years without any complications of hypertension. Exclusion criteria were patients presenting with complications of hypertension, like stroke, cerebral vascular accidents (CVA), and so forth, and patients presenting with comorbidities like diabetes mellitus, renal failure, and ischemic heart disease (IHD). These exclusion criteria were considered because patients with other comorbid conditions might require special diets; therefore, the gathered data could not be generalized to hypertensive patients.

Systolic and diastolic blood pressures (BP) were measured with a qualified care provider in the rural health center after 15 minutes of rest, while the subject was in a seated and relaxed position. Two recordings were made at a 10-minute interval with millimeter mercury $(\mathrm{mmHg})$ and the mean value of the 2 recordings (not varying by more than $5 \mathrm{mmHg}$ ) was calculated. The patients were classified as controlled hypertension ( SBP $<140 \mathrm{mmHg}$ and DBP $<90 \mathrm{mmHg}$ ) and uncontrolled hypertension (SBP $\geq 140 \mathrm{mmHg}$ and $\mathrm{DBP} \geq 90 \mathrm{mmHg}$ ) according to Seventh Report of the Joint National Committee on Prevention, Detection, Evaluation, and Treatment of High Blood Pressure (JNC 7) guidelines [29]. Body weight was measured with the participant wearing light clothing without shoes using a Seca weight scale to the nearest $0.1 \mathrm{~kg}$ and height was measured in centimeters $(\mathrm{cm})$ using a stadiometer while the participant was standing in an upright position without wearing shoes. Body mass index (BMI) was calculated as weight in $\mathrm{kg}$ divided by height in meters squared. Patients having a BMI of less than 18.5 were classified as underweight, from 18.5 to less than 25 were considered normal, and from 25 to less than 30 were overweight, whereas those more than 30 were considered obese.

Data were collected by a four-part questionnaire that consisted of the demographic data such as gender, age, educational level, systolic and diastolic blood pressure, family history, and duration of illness and salt knowledge questions (each item was prepared as part of a standard answer: correct, incorrect, or do not know); the illness perception (14 questions with 4-point Likert option) and nutritional data were gathered by a 3-day food record questionnaire. Salt knowledge scores ranged between 20 and 0 and illness perception scores were ranged from 56 to 14 .

The salt knowledge section included 20 questions about dietary recommendations on salt, salt intake and disease relationships, and the salt content of commonly eaten foods. All correct responses were scored as one, while incorrect responses which included "do not know" were assigned a score of zero.

Questionnaire was designed based on the literature review and face validity was approved by 5 experts in the field of health education in expert panel. Content validity was approved with content validity ratio (CVR) and content 
validity index (CVI) and reliability for nutritional knowledge section was 0.89 and for illness perception section was 0.92 .

Illness perceptions consisted of a 14-item self-report scale that measured patient's cognitive and emotional representations of their illness including consequences, timeline, control, identity, and causes. Its validity was confirmed by an expert panel and the test demonstrates a good Pearson's testretest correlation coefficient.

Each participant completed a 3-day food record, 2 weekdays and 1 weekend, to increase accuracy; first author provided 5 minutes of instructions to each participant on how to complete the food records. Also, participants were encouraged to consume usual amounts of typical food for the completion of the food record. Participants were asked to measure the volume of food consumed with household measurements (cups, tablespoons). After completing the food record, participants met the first author to review all the information for record accuracy and completeness and portion size of individual items on the food record. Nutritional data were analyzed by Nutritionist 4 software and sodium intake extracted.

Data were gathered by trained health professionals with interview method and SPSS version 18.0 for Windows (SPSS Inc., Chicago, IL, USA) was used for the data analysis. The demographic characteristics of the participants were reported by using descriptive statistics (frequencies, proportions, and means). The mean scores were compared with $t$-tests and one-way ANOVA and relationships were assessed by multiple linear regression and Pearsons correlation test.

\section{Results}

Sociodemographic Characteristics of the Participants. Table 1 shows the sociodemographic characteristics of the participants. Out of a total of 671 patients, $74.8 \%$ were female, 433 patients were in the controlled group and 243 participants were uncontrolled. No significant difference was found in the two groups' family history, income, and educational levels. However, significant differences were seen in gender and BMI. Accordingly, compared with the controlled group, the mean of BMI was higher in the uncontrolled group and majority of uncontrolled group were men (Table 1).

In this study, sodium intake was significantly different based on age group between controlled and uncontrolled patients. The significant differences were also seen in the amount of sodium intake in all age groups and between the controlled and uncontrolled groups. Participants aged between 30 and 40 had received significantly more sodium in both groups and significant difference in sodium intake was found between the two groups considering level of education, income, and gender. But in the uncontrolled group, no significant difference was found in gender (male versus female) $(P=0.05)$ and income $(P=0.6)$ (Table 2).

Also, there was a significant negative correlation between sodium intake and knowledge and illness perception in both controlled and uncontrolled hypertensive patients while this
TABle 1: Demographic characteristic of controlled ${ }^{1}$ and uncontrolled ${ }^{2}$ hypertensive patients.

\begin{tabular}{|c|c|c|c|}
\hline Variable & $\begin{array}{l}\text { Controlled } \\
(N=433) \\
\text { Mean } \pm \text { sd }\end{array}$ & $\begin{array}{l}\text { Uncontrolled } \\
\qquad(N=238) \\
\text { Mean } \pm \text { sd }\end{array}$ & $P$ value \\
\hline Age & $50.2 \pm 6.6$ & $50.9 \pm 6.4$ & $P=0.6$ \\
\hline Diseases duration & $5.9 \pm 4.0$ & $5.5 \pm 3.2$ & $P=0.2$ \\
\hline BMI & $29.2 \pm 4.1$ & $30.1 \pm 5.0$ & $P=0.04$ \\
\hline $\begin{array}{l}\text { Systolic blood } \\
\text { pressure }\end{array}$ & $133.3 \pm 7.5$ & $153.5 \pm 5.1$ & $P<0.001$ \\
\hline \multirow[t]{2}{*}{$\begin{array}{l}\text { Diastolic blood } \\
\text { pressure }\end{array}$} & $84.1 \pm 5.4$ & $91.1 \pm 5.5$ & $P<0.001$ \\
\hline & $N(\%)$ & $N(\%)$ & \\
\hline \multicolumn{4}{|l|}{ Literature level } \\
\hline Primary school & $335(77.4 \%)$ & $173(73.1 \%)$ & \multirow{3}{*}{$P=0.3$} \\
\hline Mid school & $89(20.6 \%)$ & $58(23.5 \%)$ & \\
\hline High school & $9(2.1 \%)$ & $8(3.4 \%)$ & \\
\hline \multicolumn{4}{|l|}{ Income } \\
\hline $\begin{array}{l}\text { Up to } 4 \text { million } \\
\text { rial }\end{array}$ & $192(44.3 \%)$ & $91(38.2 \%)$ & \multirow{3}{*}{$P=0.2$} \\
\hline 4-6 million rial & $174(40.2 \%)$ & $110(46.2 \%)$ & \\
\hline $\begin{array}{l}\text { More than } 6 \\
\text { million rial }\end{array}$ & $67(15.5 \%)$ & $37(15.5 \%)$ & \\
\hline \multicolumn{4}{|l|}{ Gender } \\
\hline Male & $95(21.9 \%)$ & $74(31.1 \%)$ & \multirow{2}{*}{$P=0.01$} \\
\hline Female & $338(78.1 \%)$ & $164(68.9 \%)$ & \\
\hline \multicolumn{4}{|l|}{ Family history } \\
\hline Yes & 215 (49.7\%) & $116(48.7 \%)$ & \multirow{2}{*}{$P=0.8$} \\
\hline No & $218(50.3 \%)$ & $122(51.3 \%)$ & \\
\hline
\end{tabular}

${ }^{1}$ Controlled hypertensive patients: $\mathrm{SBP}<140 \mathrm{mmHg}$ and DBP $<90 \mathrm{mmHg}$.

${ }^{2}$ Uncontrolled hypertensive patients: SBP $\geq 140 \mathrm{mmHg}$ and DBP $\geq$ $90 \mathrm{mmHg}$.

correlation was greater among the uncontrolled patients (Table 4).

Using multiple linear regressions, the impact of the predictor variables on sodium intake was examined. The results of regression analysis were significant, after adjusting for energy intake, suggesting that the knowledge and illness perception variables accounted for $\left(R^{2}\right) 13.6 \%$ of the variance in sodium intake in the controlled group and these variables predicted $47.2 \%$ of sodium intake in the uncontrolled patients. Other variables such as age, sex, disease duration, weight, and education were also entered into the model that did not have any significant relationship with the dependent variable (Table 5).

\section{Discussion}

Hypertension progressively and permanently damages target organs, leading to life-threatening complications and death [30]. Considering the importance of nutrition's role in the 
TABLE 2: Sodium intake among controlled ${ }^{1}$ and uncontrolled $^{2}$ hypertensive patients.

\begin{tabular}{lccl}
\hline Variables & $\begin{array}{c}\text { Controlled } \\
(N=433) \\
\text { Mean } \pm \text { sd }\end{array}$ & $\begin{array}{c}\text { Uncontrolled } \\
(N=238) \\
\text { Mean } \pm \text { sd }\end{array}$ & P value \\
\hline Age & & & \\
30-40 years & $2752 \pm 462$ & $3879 \pm 436$ & \\
41-50 years & $2562 \pm 565$ & $3575 \pm 250$ & $P<0.001$ \\
51-60 years & $2712 \pm 521$ & $3591 \pm 222$ & \\
$P$ value & $P=0.01$ & $P<0.001$ & \\
Literature level & & & \\
Primary school & $2691 \pm 545$ & $3593 \pm 230$ & \\
Mid school & $2498 \pm 510$ & $3649 \pm 545$ & $P<0.001$ \\
High school & $2826 \pm 389$ & $3399 \pm 69$ & \\
$P$ value & $P=0.007$ & $P=0.03$ & \\
Income & & & \\
Up to 4 million rial & $2562 \pm 591$ & $3598 \pm 229$ & \\
4-6 million rial & $2773 \pm 493$ & $3613 \pm 274$ & $P=0.001$ \\
More than 6 million rial & $2607 \pm 446$ & $3564 \pm 279$ & \\
$P$ value & $P=0.01$ & $P=0.6$ & \\
Gender & & & \\
Male & & & \\
Female & $2473 \pm 558$ & $3552 \pm 216$ & \\
$P$ value & $2705 \pm 525$ & $3621 \pm 273$ & $P<0.001$ \\
\hline
\end{tabular}

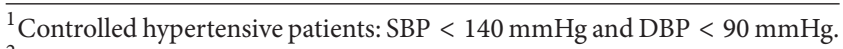

${ }^{2}$ Uncontrolled hypertensive patients: SBP $\geq 140 \mathrm{mmHg}$ and DBP $\geq$ $90 \mathrm{mmHg}$.

hypertension control and the role of illness perception and nutritional knowledge in the nutritional adherence, to our knowledge, this is the first study which has examined the relationship between illness perception and knowledge with dietary sodium intake in rural hypertensive patients.

In the present study, no significant differences were seen between the two groups in demographic variables (age, income, educational level, and duration of disease) so it could be said that these two groups were similar in terms of demographic characteristics. In the present study, the mean score of illness perception significantly was higher in the controlled group. Perceptions and beliefs have an important role in the health and health behaviors $[31,32]$.

Some individuals did not have information about amount of needed salt per day [33]. In Grimes et al. (2009), 73\% of participants were not informed of the maximum allowed amount of salt [34]. Lack of knowledge is one of the other barriers to reduce sodium intake in patients. In a qualitative study a patient said that "my doctor said that I do not add salt to food, and I have no other information" [35]. So compared with those with negative attitudes, people who have more knowledge are more likely to have healthy behavior and reduce their sodium intake [36].

In the present study, salt knowledge of the controlled patients was moderate while knowledge of the uncontrolled
TABLE 3: Mean and standard deviation studied variables among controlled and uncontrolled hypertensive patients.

\begin{tabular}{lccc}
\hline Variables & $\begin{array}{c}\text { Controlled } \\
(N=433) \\
\text { Mean } \pm \text { sd }\end{array}$ & $\begin{array}{c}\text { Uncontrolled } \\
(N=238) \\
\text { Mean } \pm \mathrm{sd}\end{array}$ & $P$ value \\
\hline $\begin{array}{l}\text { Dietary sodium intake } \\
\text { (mg per day) }\end{array}$ & $2654 \pm 540$ & $3599 \pm 258$ & $P<0.001$ \\
$\begin{array}{l}\text { Total energy intake } \\
\text { Kcl) }\end{array}$ & $2420 \pm 392$ & $2755 \pm 310$ & $P<0.001$ \\
$\begin{array}{l}\text { Knowledge } \\
\text { Illness perception }\end{array}$ & $15.1 \pm 3.2$ & $11.3 \pm 4.5$ & $P<0.001$ \\
\hline
\end{tabular}

TABle 4: Correlation of knowledge and illness perception with sodium intake.

\begin{tabular}{lcc}
\hline \multirow{2}{*}{ Variables } & \multicolumn{2}{c}{ Pearson correlation } \\
& Correlation coefficient & $P$ value \\
\hline Controlled group $(N=433)$ & & \\
$\quad$ Illness perception & -0.381 & $P<0.001$ \\
$\quad$ Knowledge & -0.268 & $P<0.001$ \\
Uncontrolled group $(N=238)$ & & \\
$\quad$ Illness perception & -0.666 & $P<0.001$ \\
$\quad$ Knowledge & -0.652 & $P<0.001$ \\
\hline
\end{tabular}

group was not acceptable. Considering the fact that in Iran patients take a continuous and free care by doctors and health workers in rural health centers, having a higher knowledge expectation of patients is not unreasonable. Our finding is consistent with similar studies conducted in Iran [30] and the study done by Oliveria et al. (2005) who obtained a similar result [37].

Compared with the controlled group, the mean of sodium intake in the uncontrolled group was significantly higher. Controlled group significantly had higher mean scores in the knowledge and illness perception. In the present study, the mean of sodium intake in the uncontrolled group was $3599 \pm 258$ which was significantly greater than the controlled group $(2654 \pm 540)(P<0.001)$ (Table 3$)$.

Despite this level of knowledge, patients were shown incorrect information about some aspects. In this study, for the question "hypertension dietary was only restricted for salt" about half of the patients gave the wrong answer. In the same study, the misinformation about the disease has been reported [37]. But in Chinese study, patient's knowledge was reported much lower and they had little information on nutrition [38].

In this study, based on education, income, and gender, no significant difference was found in sodium intake between the controlled and uncontrolled groups. These findings were consistent with other studies in this field and the differences between the feeding habits were attributed to demographic factors such as age, sex, education, and income [39].

Salt intake was attributed to demographic factors and those middle-aged male participants with lower income and 
TABLE 5: Multiple linear regressions of knowledge and illness perception in sodium intake variations (adjusted to energy intake).

\begin{tabular}{|c|c|c|c|c|c|c|}
\hline \multirow{2}{*}{ Variables } & \multicolumn{4}{|c|}{ Multiple linear regressions } & \multirow{2}{*}{$R^{2}$} & \multirow{2}{*}{ Adjusted $R$ square } \\
\hline & Beta & Std. error & $t$ & $P$ value & & \\
\hline \multicolumn{7}{|c|}{ Controlled group $(N=433)$} \\
\hline \multicolumn{7}{|l|}{ Model 1} \\
\hline Illness perception & -0.232 & 2.4 & -4.9 & $P<0.001$ & \multirow{2}{*}{0.136} & \multirow{2}{*}{0.132} \\
\hline Knowledge & -0.222 & 6.7 & -4.7 & $P<0.001$ & & \\
\hline Model 2 & \multicolumn{4}{|c|}{ Model $1+$ weight, age, diseases duration, gender } & 0.152 & 0.140 \\
\hline \multicolumn{7}{|c|}{ Uncontrolled group $(N=238)$} \\
\hline \multicolumn{7}{|c|}{ Model 1} \\
\hline Illness perception & -0.362 & 3.6 & -3.6 & $P<0.001$ & \multirow{2}{*}{0.472} & \multirow{2}{*}{0.467} \\
\hline Knowledge & -0.346 & 5.5 & -3.4 & $P=0.001$ & & \\
\hline Model 2 & \multicolumn{4}{|c|}{ Model 1 + weight, age, diseases duration, gender } & 0.498 & 0.485 \\
\hline
\end{tabular}

lower education consumed more salt $[1,40]$. However, in the present study, women received more sodium than men which is inconsistent with the results of previous studies such as Chung et al. (2004) [41] and Sheahan and Fields (2008) [35] in which the women consumed less salt.

These differences in results might be justified by the social and cultural paradox and nutritional pattern in Iranian rural areas and industrialized countries; however, further investigations are needed to find more comprehensive patterns of diet, especially in rural areas. But the importance of this study was explained by the fact that demographic factors could not be changed. Accordingly, only patient's perceptions and knowledge could be addressed with interventions. Sodium intake in the uncontrolled group was significantly higher, more than double the recommended amount [42, 43]; considering that salty taste in foods is desirable among Iranian people [33], this finding was expected.

But these patients are at high risk for complications of hypertension and it is very disturbing. However, despite that Iranian people are being cared for in the rural health care centers, the recommendations should be presented to them and high salt intake causes need a wider range of investigation. In a study conducted in Iran, adult women consumed 10 grams of salt per day which was 1.5 times more than the recommended daily amount [33]. No similar study on hypertensive patients was found in Iran, but the amount of sodium in American hypertensive patients was also 2.2 times more than the recommended dose [44].

The salty taste of food was stated as an important predictor of high salt consumption [45] and is considered as an important challenge for health workers. Excessive salt consumption in people who are accustomed to the salty taste is very difficult and requires a set of interventions. Meanwhile, the excess sodium intake is associated with increased blood pressure [1] and significantly increases the risk of heart attack $[46,47]$.

High blood pressure is a major factor in the etiology of cardiovascular disease [1]. Studies have demonstrated the importance of sodium in hypertension control repeatedly. For example, it is clear that reducing the sodium intake in patients and healthy subjects for 4 weeks or more, results in a significant reduction in blood pressure [48].
Pearson's correlation and linear regression showed negative significant relationships between knowledge and perceptions with sodium intake. In addition, the correlations were higher for both variables among the uncontrolled hypertensive group. Also, multiple linear regressions showed that knowledge and perception could predict $13.5 \%$ of the variation in sodium intake in controlled group while this value was $47.2 \%$ in uncontrolled group, respectively. It could be concluded that these two variables could play an important role in the feeding behaviors of the patient; this role was seen mainly among the uncontrolled group patients.

However, knowledge and perceptions play important roles in disease control and patient compliance; however, they do not guarantee patients' health behavior [32]. In addition to these variables, attention should be given to environmental factors such as health careers because blood pressure is influenced by many factors and this rate of prediction can be considered a very good prediction of the knowledge and perception. Vallés-Fernandez et al. (2009) in their study showed that blood pressure was uncontrollable, despite the good knowledge in patients. This was so because controlling $\mathrm{BP}$ was influenced by several factors including the patientrelated factors (age, BMI, and lifestyle), factors associated with treatment, clinical evaluation factors (treatment techniques), and factors associated with medical equipment and facilities [49]. Also, in a similar study in Iran, despite good knowledge and attitudes of patients, blood pressure was not controlled [30]. Considering the same results, a detailed and comprehensive study about the causes of BP controlling is needed; it seems that in the current situation, all attention is paid to the patients and they will be recognized as original extradite but the fact is that patients have not participated in care designing and their participation is not considered. Evidences in some contexts indicated that the most important obstacle introduced to control blood pressure includes personnel's failure in implementing recommended health care [50].

This study had several limitations. First, as a crosssectional study, the findings could only be used to examine associations and not to draw inferences regarding causality. Second, the model only explained about the variation in sodium intake. Therefore, future studies should be extended 
to study other factors which may mediate the relationship between socio-demographic factors and sodium intake such as self-efficacy, attitudes, and salt taste and finally, an overrepresentation of females occurred despite the use of random sampling methods which was another limitation in this study. This was due to greater compliance and a willingness among women to participate. In contrast, the multiple regression analysis, the optimal sample size, and the standard tools are the strengths of this study. The other strength, according to our knowledge, is that few studies have been done on the rural hypertensive patients even in urban patients in Iran and developing countries. In this study, dietary intake was assessed with 3 days of food recording instead of food recall, because $24 \mathrm{~h}$ food recall depended on memory and studies showed underreporting error with food recall tool [51, 52]; therefore, the results were more likely to be closer to reality.

\section{Conclusions}

Knowledge and illness perception play an important role in prediction of sodium intake variation in hypertensive patients. Therefore, the importance of paying more attention to these two variables in the design of interventions by health network planners and health professionals is essential. It seems necessary to explore the sources of patients' information and perceptions. Furthermore, trying to improve and update patients' information and providing a clear picture of the condition to influence their perceptions of their disease are also required.

\section{Conflict of Interests}

The authors declare that there is no conflict of interests.

\section{References}

[1] R. Sarmugam, A. Worsley, and W. Wang, "An examination of the mediating role of salt knowledge and beliefs on the relationship between socio-demographic factors and discretionary salt use: a cross-sectional study," The International Journal of Behavioral Nutrition and Physical Activity, vol. 10, article 25, 2013.

[2] D. S. Lee, J. M. Massaro, T. J. Wang et al., "Antecedent blood pressure, body mass index, and the risk of incident heart failure in later life," Hypertension, vol. 50, no. 5, pp. 869-876, 2007.

[3] F. Noohi, M. Maleki, and S. Orei, "Hypertension," in Epidemiology and Control of Common Disorders in Iran, F. Azizi, H. Hatami, and M. Janghorbani, Eds., pp. 23-30, Eshtiagh Press, Tehran, Iran, 2nd edition, 2001.

[4] A.-A. Haghdoost, B. Sadeghirad, and M. Rezazadehkermani, "Epidemiology and heterogeneity of hypertension in Iran: a systematic review," Archives of Iranian Medicine, vol. 11, no. 4, pp. 444-452, 2008.

[5] T. G. Pickering, "Why are we doing so badly with the control of hypertension? Poor compliance is only part of the story," Journal of Clinical Hypertension, vol. 3, no. 3, pp. 179-182, 2001.

[6] E. Sabaté, Adherence to Long-Term Therapies: Evidence for Action, World Health Organization, 2003.

[7] C.-Y. Hsiao, C. Chang, and C.-D. Chen, "An investigation on illness perception and adherence among hypertensive patients,"
Kaohsiung Journal of Medical Sciences, vol. 28, no. 8, pp. 442447, 2012.

[8] K. J. Petrie, L. A. Jago, and D. A. Devcich, “The role of illness perceptions in patients with medical conditions," Current Opinion in Psychiatry, vol. 20, no. 2, pp. 163-167, 2007.

[9] K. J. Petrie and J. Weinman, "Why illness perceptions matter," Clinical Medicine, vol. 6, no. 6, pp. 536-539, 2006.

[10] B. M. Egan and J. N. Basile, "Controlling blood pressure in $50 \%$ of all hypertensive patients: an achievable goal in the healthy people 2010 report?" Journal of Investigative Medicine, vol. 51, no. 6, pp. 373-385, 2003.

[11] C. R. Nelson and D. A. Knapp, "Trends in antihypertensive drug therapy of ambulatory patients by US office-based physicians," Hypertension, vol. 36, no. 4, pp. 600-603, 2000.

[12] N. R. Kressin, F. Wang, J. Long et al., "Hypertensive patients' race, health beliefs, process of care, and medication adherence," Journal of General Internal Medicine, vol. 22, no. 6, pp. 768-774, 2007.

[13] P. B. Mellen, S. K. Gao, M. Z. Vitolins, and D. C. Goff Jr., "Deteriorating dietary habits among adults with hypertension: dash dietary accordance, NHANES 1988-1994 and 1999-2004," Archives of Internal Medicine, vol. 168, no. 3, pp. 308-314, 2008.

[14] C. D. Ndumele, S. Shaykevich, D. Williams, and L. S. Hicks, "Disparities in adherence to hypertensive care in urban ambulatory settings," Journal of Health Care for the Poor and Underserved, vol. 21, no. 1, pp. 132-143, 2010.

[15] L. Azadbakht, N. R. P. Fard, M. Karimi et al., "Effects of the Dietary Approaches to Stop Hypertension (DASH) eating plan on cardiovascular risks among type 2 diabetic patients: a randomized crossover clinical trial," Diabetes Care, vol. 34, no. 1, pp. 55-57, 2011.

[16] F. Shirani, A. Salehi-Abargouei, and L. Azadbakht, "Effects of Dietary Approaches to Stop Hypertension (DASH) diet on some risk for developing type 2 diabetes: a systematic review and meta-analysis on controlled clinical trials," Nutrition, vol. 29, no. 7-8, pp. 939-947, 2013.

[17] L. Azadbakht, P. Mirmiran, A. Esmaillzadeh, T. Azizi, and F. Azizi, "Beneficial effects of a dietary approaches to stop hypertension eating plan on features of the metabolic syndrome," Diabetes Care, vol. 28, no. 12, pp. 2823-2831, 2005.

[18] S. Cornell and A. Briggs, "Newer treatment strategies for the management of type 2 diabetes mellitus," Journal of Pharmacy Practice, vol. 17, no. 1, pp. 49-54, 2004.

[19] A. S. Truswell, "What nutrition knowledge and skills do primary care physicians need to have, and how should this be communicated?" European Journal of Clinical Nutrition, vol. 53, supplement 2, pp. S67-S71, 1999.

[20] Y. M. Chan and A. Molassiotis, "The relationship between diabetes knowledge and compliance among Chinese with noninsulin dependent diabetes mellitus in Hong Kong," Journal of Advanced Nursing, vol. 30, no. 2, pp. 431-438, 1999.

[21] M. Pirouznia, "The association between nutrition knowledge and eating behavior in male and female adolescents in the US," International Journal of Food Sciences and Nutrition, vol. 52, no. 2, pp. 127-132, 2001.

[22] H. N. Bashour, "Survey of dietary habits of in-school adolescents in Damascus, Syrian Arab Republic," Eastern Mediterranean Health Journal, vol. 10, no. 6, pp. 853-862, 2004.

[23] R. Sakamaki, K. Toyama, R. Amamoto, C.-J. Liu, and N. Shinfuku, "Nutritional knowledge, food habits and health attitude of Chinese university students-a cross sectional study," Nutrition Journal, vol. 4, article 4, 2005. 
[24] S. B. Erkoc, B. Isikli, S. Metintas, and C. Kalyoncu, "Hypertension Knowledge-Level Scale (HK-LS): a study on development, validity and reliability," International Journal of Environmental Research and Public Health, vol. 9, no. 3, pp. 1018-1029, 2012.

[25] S. Sanne, P. Muntner, L. Kawasaki, A. Hyre, and K. B. Desalvo, "Hypertension knowledge among patients from an urban clinic," Ethnicity and Disease, vol. 18, no. 1, pp. 42-47, 2008.

[26] H. R. Han, K. Chan, H. Song, T. Nguyen, J. E. Lee, and M. T. Kim, "Development and evaluation of a hypertension knowledge test for Korean hypertensive patients," Journal of Clinical Hypertension, vol. 13, no. 10, pp. 750-757, 2011.

[27] H.-R. Han, J. Kim, K. B. Kim et al., "Implementation and success of nurse telephone counseling in linguistically isolated Korean American patients with high blood pressure," Patient Education and Counseling, vol. 80, no. 1, pp. 130-134, 2010.

[28] C. R. Dennison, W. S. Post, M. T. Kim et al., "Underserved urban African American men: hypertension trial outcomes and mortality during 5 years," American Journal of Hypertension, vol. 20, no. 2, pp. 164-171, 2007.

[29] A. V. Chobanian, G. L. Bakris, H. R. Black et al., "Seventh report of the Joint National Committee on Prevention, Detection, Evaluation, and Treatment of High Blood Pressure," Hypertension, vol. 42, no. 6, pp. 1206-1252, 2003.

[30] F. Sabouhi, S. Babaee, H. Naji, and A. H. Zade, "Knowledge, awareness, attitudes and practice about hypertension in hypertensive patients referring to public health care centers in Khoor \& Biabanak 2009," Iranian Journal of Nursing and Midwifery Research, vol. 16, no. 1, pp. 35-41.

[31] P. Lukoschek, "African Americans' beliefs and attitudes regarding hypertension and its treatment: a qualitative study," Journal of Health Care for the Poor and Underserved, vol. 14, no. 4, pp. 566-587, 2003.

[32] C. D. Ford, M. J. Kim, and B. L. Dancy, "Perceptions of hypertension and contributing personal and environmental factors among rural Southern African American women," Ethnicity \& Disease, vol. 19, no. 4, pp. 407-413, 2009.

[33] Z. Motlagh, S. Mazloomy, H. M. Khosravi, M. Morowatisharifabad, and M. Askarshahi, "Salt intake among women refer to medical health centers, Yazd, Iran, 2011," Journal of Shahid Sadoughi University of Medical Sciences, vol. 19, no. 4, pp. 550560, 2011.

[34] C. A. Grimes, L. J. Riddell, and C. A. Nowson, "Consumer knowledge and attitudes to salt intake and labelled salt information," Appetite, vol. 53, no. 2, pp. 189-194, 2009.

[35] S. L. Sheahan and B. Fields, "Sodium dietary restriction, knowledge, beliefs, and decision-making behavior of older females," Journal of the American Academy of Nurse Practitioners, vol. 20, no. 4, pp. 217-224, 2008.

[36] J. Zhang, A. Q. Xu, J. X. Ma et al., "Dietary sodium intake: knowledge, attitudes and practices in Shandong province, China," PLoS ONE, vol. 8, no. 3, Article ID e58973, 2013.

[37] S. A. Oliveria, R. S. Chen, B. D. McCarthy, C. C. Davis, and M. N. Hill, "Hypertension knowledge, awareness, and attitudes in a hypertensive population," Journal of General Internal Medicine, vol. 20, no. 3, pp. 219-225, 2005.

[38] X. Li, N. Ning, Y. Hao et al., "Health literacy in rural areas of China: hypertension knowledge survey," International Journal of Environmental Research and Public Health, vol. 10, no. 3, pp. 1125-1138, 2013.

[39] A. K. Kant and B. I. Graubard, "Secular trends in the association of socio-economic position with self-reported dietary attributes and biomarkers in the US population: National Health and Nutrition Examination Survey (NHANES) 1971-1975 to NHANES 1999-2002," Public Health Nutrition, vol. 10, no. 2, pp. 158-167, 2007.

[40] C. A. Grimes, L. J. Riddell, and C. A. Nowson, "The use of table and cooking salt in a sample of Australian adults," Asia Pacific Journal of Clinical Nutrition, vol. 19, no. 2, pp. 256-260, 2010.

[41] M. L. Chung, D. K. Moser, and T. A. Lennie, "Women are more adherent to low sodium diet recommendations than men," Journal of Cardiac Failure, vol. 10, supplement 4, article 21, 2004.

[42] Dietary Guidelines for Americans, US Department of Agriculture, US Department of Health and Human Services, 2005.

[43] Healthy People 2010 with Understanding and Improving Health and Objectives for Improving Health, US Government Printing Office, Washington, DC, USA, 2000.

[44] C. Ayala, C. Gillespie, M. Cogswell, N. L. Keenan, and R. Merritt, "Sodium consumption among hypertensive adults advised to reduce their intake: National Health and Nutrition Examination Survey, 1999-2004," Journal of Clinical Hypertension, vol. 14, no. 7, pp. 447-454, 2012.

[45] J. E. van der Veen, C. de Graaf, S. J. van Dis, and W. A. van Staveren, "Determinants of salt use in cooked meals in the Netherlands: attitudes and practices of food preparers," European Journal of Clinical Nutrition, vol. 53, no. 5, pp. 388-394, 1999.

[46] P. Strazzullo, L. D’Elia, N.-B. Kandala, and F. P. Cappuccio, "Salt intake, stroke, and cardiovascular disease: meta-analysis of prospective studies," BMJ, vol. 339, article b4567, 2009.

[47] H. Gardener, T. Rundek, C. B. Wright, M. S. V. Elkind, and R. L. Sacco, "Dietary sodium and risk of stroke in the Northern Manhattan study," Stroke, vol. 43, no. 5, pp. 1200-1205, 2012.

[48] F. J. He, J. Li, and G. A. Macgregor, "Effect of longer term modest salt reduction on blood pressure: cochrane systematic review and meta-analysis of randomised trials," BMJ, vol. 346, article f1325, 2013.

[49] R. Vallès-Fernandez, M. Rosell-Murphy, O. Correcher-Aventin et al., "A quality improvement plan for hypertension control: the INCOTECA Project (INterventions for COntrol of hyperTEnsion in CAtalonia)," BMC Public Health, vol. 9, article 89, 2009.

[50] D. Siegel, "Barriers to and strategies for effective blood pressure control," Vascular Health and Risk Management, vol. 1, no. 1, pp. 9-14, 2005.

[51] J. Zhang, E. H. M. Temme, S. Sasaki, and H. Kesteloot, "Underand overreporting of energy intake using urinary cations as biomarkers: relation to body mass index," American Journal of Epidemiology, vol. 152, no. 5, pp. 453-462, 2000.

[52] D. W. Heerstrass, M. C. Ocké, H. B. Bueno-De-Mesquita, P. H. M. Peeters, and J. C. Seidell, "Underreporting of energy protein and potassium intake in relation to body mass index," International Journal of Epidemiology, vol. 27, no. 2, pp. 186-193, 1998. 


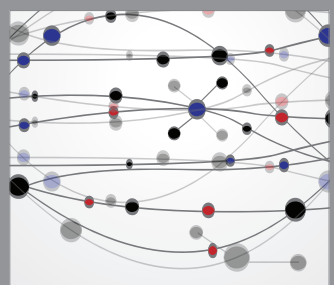

The Scientific World Journal
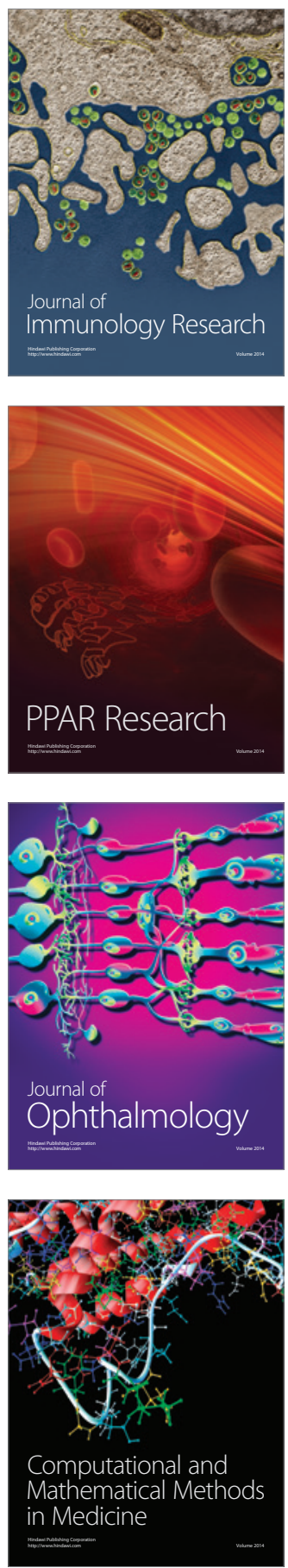

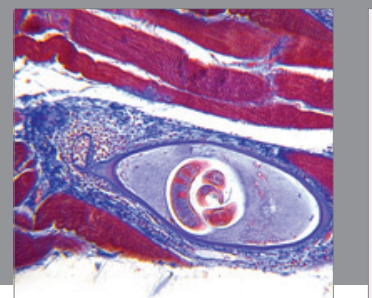

Gastroenterology

Research and Practice
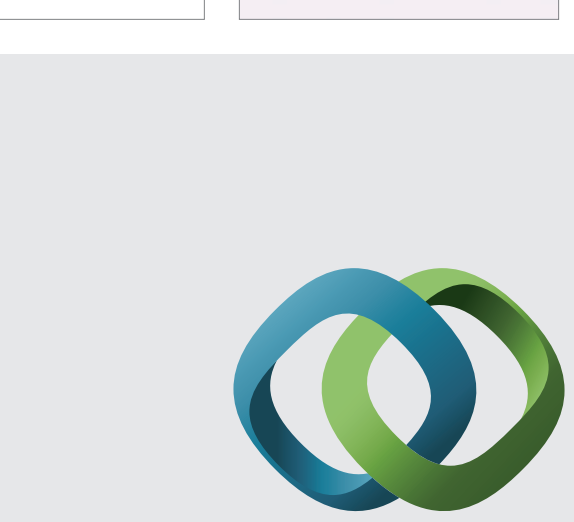

\section{Hindawi}

Submit your manuscripts at

http://www.hindawi.com
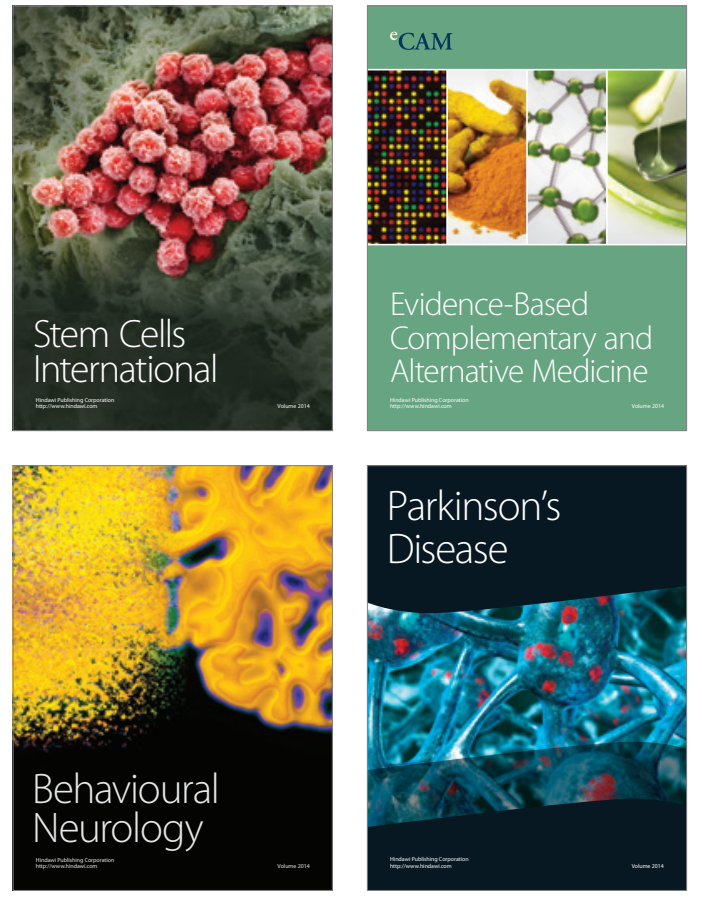
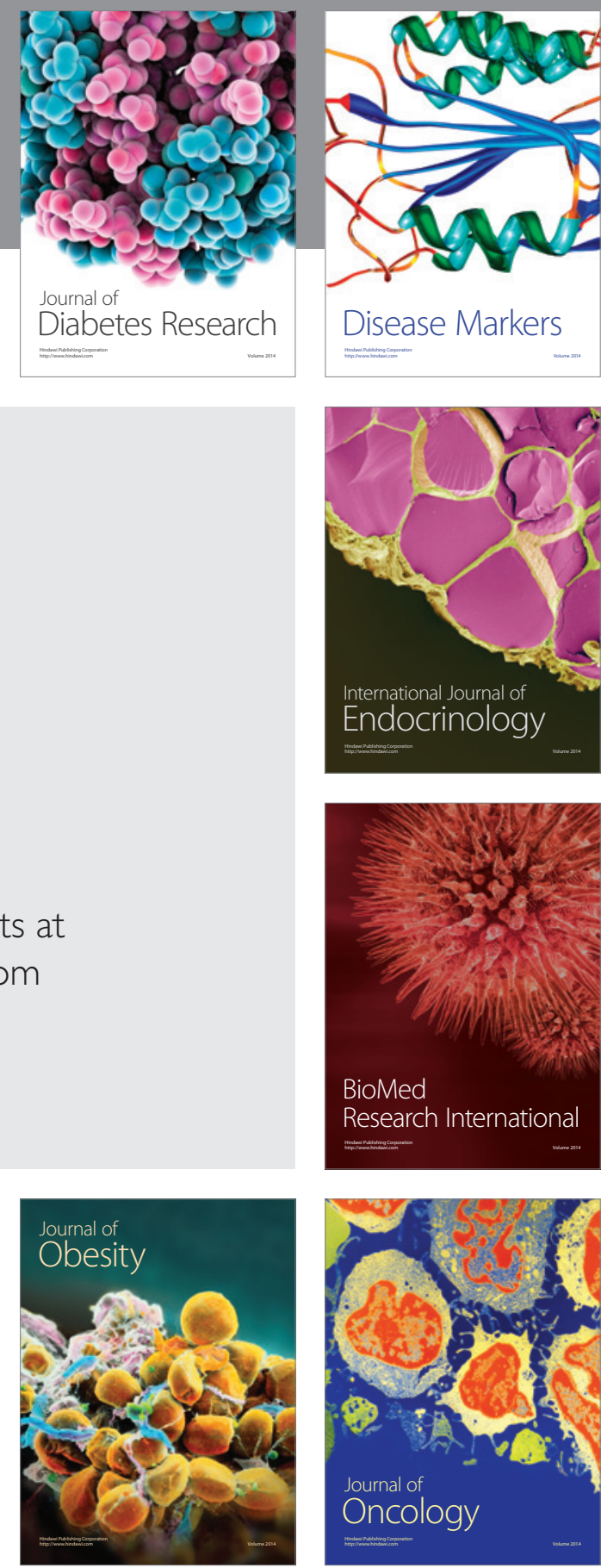

Disease Markers
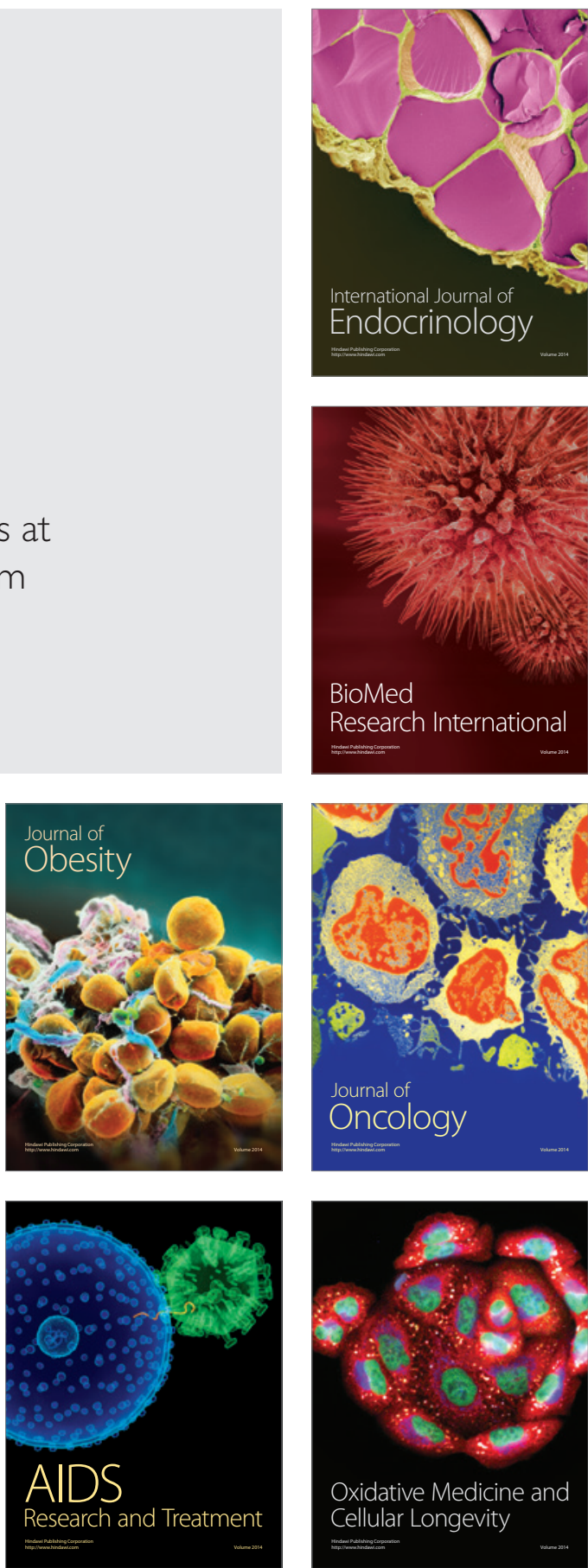